J. Electroanal. Chem, 246 (1988) 165-180

Elsevier Sequoia S.A., Lausanne - Printed in The Netherlands

\title{
MODIFICATIONS OF PALLADIUM ELECTRODE SURFACES PRODUCED BY PERIODIC POTENTIAL TREATMENTS
}

\author{
C.L. PERDRIEL, E. CUSTIDIANO and A.J. ARVIA \\ Instituto de Investigaciones Fisicoquimicas Téricas y Aplicadas (INIFTA), Facultad de Ciencias Exactas, \\ Universidad Nacional de La Plata, Casilla de Correo 16, Sucursal 4, (1900) La Plata (Argentina)
}

(Received 11th May 1987; in revised form 4th January 1988)

\begin{abstract}
The electrochemical treatment of Pd electrodes in acid solutions by means of periodic potentials applied within certain potential windows in the range $0-1.5 \mathrm{~V}$ (vs. RHE) and frequencies in the range $0.5-6.25 \mathrm{kHz}$, produces surface modifications involving different types of roughening and faceting. These modifications are the consequences of various electrochemical reactions occurring during the oxidation-reduction cycles, mainly associated with the electrodissolution-electrodeposition of Pd, and oxide layer formation-electroreduction processes. Quantitative data are shown about the former conjugated processes which indicate that, depending on the frequency range, at least three different mechanisms operate for the entire reaction. Surface modifications are followed through voltammetry, scanning electron microscopy and scanning tunneling micróscopy.
\end{abstract}

\section{(I) INTRODUCTION}

Relatively fast periodic potentials of different waveforms confined to the potential window of $\mathrm{H}$ and $\mathrm{O}$ atom electroadsorption-electrodesorption applied to fcc noble metals in contact with acid solution produce electrochemical faceting effects with or without roughening [1-4] through a mechanism involving the periodic electrodissolution and selective electrodeposition of metal ions. The overall process including the corresponding treated surface characteristics as derived from electrochemical data, scanning electron and tunneling microscopy images, can be accounted for qualitatively through the Monte Carlo simulation procedure [5]. According to the mechanism of electrochemical faceting, it appears that the solubility of the metal salt resulting in the electrodissolution reaction at the vicinity of the electrode surface could influence the conditions of the process itself.

The electrodissolution of a $\mathrm{Pd}$ electrode in contact with dilute $\mathrm{H}_{2} \mathrm{SO}_{4}$ under triangular potential scanning at $0.040 \mathrm{~V} / \mathrm{s}$ between $0.33 \mathrm{~V}$ (vs. RHE) and $1.54 \mathrm{~V}$ amounts to $0.18 \mu \mathrm{g} \mathrm{cm}^{-2}$ cycle of metal, and the rate of electrodissolution increases 
with temperature [6,7]. In these cases the appearance of measurable amounts of electrodissolved Pd occurs inasmuch as the upper limit of the periodic potential exceeds the equilibrium potential of the $\mathrm{Pd} / \mathrm{Pd}^{2+}$ electrode. Otherwise, the electrodissolution of $\mathrm{Pd}$ under a constant step, either in dilute $\mathrm{HClO}_{4}$ [8] or $\mathrm{H}_{2} \mathrm{SO}_{4}$ [9], reaches a maximum value of $1.5 \times 10^{-3} \mu \mathrm{g} \mathrm{cm}^{-2} \mathrm{~s}^{-1}$ at $0.99 \mathrm{~V}$, and it decreases to $1.3-1.5 \times 10^{-4} \mu \mathrm{g} \mathrm{cm}^{-2} \mathrm{~s}^{-1}$ in the 1.14-1.74 $\mathrm{V}$ range because passivation of the metal sets in. Furthermore, Pd electrodissolution is favoured in those electrolyte solutions containing more strongly adsorbable anions $[10,11]$. Likewise the chronopotentiometric electroreduction of $\mathrm{O}_{2}$ and $\mathrm{H}_{2} \mathrm{O}_{2}$ on $\mathrm{Pd}$ in $1 \mathrm{M} \mathrm{H}_{2} \mathrm{SO}_{4}$ indicates the existence of $\mathrm{PdO}$ and $\mathrm{PdO}_{2}$ and the formation of a finely divided $\mathrm{Pd}$ overlayer [12]. The latter, which can also be formed through repetitive oxidation-reduction cycles, produces an increase in the electrode roughness which decreases with time, suggesting some surface atom rearrangement at the overlayer level or some preferential dissolution. The sensitivity of Pd to surface interactions has been demonstrated through the surface structure change of $\mathrm{Pd}$ (111) single crystals upon $\mathrm{O}$ adsorption [13]. This process is accompanied by $\mathrm{O}$ absorption into bulk Pd. Similar types of processes occur also for Pd (100) single crystals [14].

This paper is devoted to investigating morphological changes produced on the surface of Pd electrodes in acid by periodic potential treatments similar to those employed in the electrochemical faceting of other metals such as Pt [1,2], Au [15] and Rh [16]. Roughening and electrochemical faceting conditions for Pd can be modified substantially by changing the frequency and potential window of the periodic potential applied to the electrode, although the lack of electrochemical data concerning the electrochemical adsorption behaviour of single crystal Pd surfaces impedes definitive characterisation of the surface modifications.

\section{(II) EXPERIMENTAL}

Runs were made using a low resistance Pyrex glass cell, comprised of two cylindrical compartments, one of them of ca. $10 \mathrm{~cm}^{3}$ for housing the working electrode and the counter electrode, and the other for the reference electrode.

The Pd working electrodes were prepared from a piece of Pd wire (Johnson Matthey Chem. Co., 99.999\%) of $0.2 \mathrm{~cm}^{2}$ apparent area, which was pretreated as follows: (i) polishing with $0.3 \mu \mathrm{m}$ grit alumina powder; (ii) immersion in concentrated $\mathrm{H}_{2} \mathrm{SO}_{4}$; (iii) rinsing in Milli-Q water; and (iv) potential cycling during 15 min in $1 \mathrm{M} \mathrm{H}_{2} \mathrm{SO}_{4}$ at $0.10 \mathrm{~V} / \mathrm{s}$ between 0.33 and $1.40 \mathrm{~V}$ (vs. RHE). Other $\mathrm{Pd}$ working electrodes were spherical microelectrodes made by melting the tip of a Pd wire in an oxygen-gas torch flame and cooling in air. Most of these electrodes consist of a few crystallographic grains with well-defined grain boundaries.

A large area graphite counter electrode was used in those runs intended for evaluating the amount of dissolved Pd produced at the working electrode. Occasionally, a Pd counter electrode was also employed. A conventional reversible hydrogen electrode in $1 \mathrm{M} \mathrm{H}_{2} \mathrm{SO}_{4}$ was used as reference. 
The type of experiments carried out with Pd electrodes was the same as described previously for Pt [17]. In principle, a periodic potential of any waveform is characterized by the frequency $(f)$, upper $\left(E_{\mathrm{u}}\right)$ and lower $\left(E_{1}\right)$ switching potentials, and the time of the positive and negative half periods, respectively. For a symmetric square wave $\tau_{u}=\tau_{1}=\tau$, whereas for an asymmetric one either $\tau_{1}>\tau_{u}$ or $\tau_{1}<\tau_{u}$, Analogously, for a triangular sweep in the positive and negative directions the half cycles of the potential perturbation are denoted by $\tau_{\mathrm{a}}$ and $\tau_{\mathrm{c}}$, respectively. The Pd working electrodes were subjected to either repetitive triangular (RTPS) or repetitive square wave potential sweep (RSWPS) (electrochemical treatment) within different frequency and potential limits, namely for RTPS; $E_{\mathrm{u}}=1.40 \mathrm{~V}, E_{1}=0.33 \mathrm{~V} ; 0.1$ $\mathrm{V} / \mathrm{s} \leqslant v \leqslant 5000 \mathrm{~V} / \mathrm{s}$; and for RSWPS, $0.20 \mathrm{~V} \leqslant E_{1} \leqslant 0.60 \mathrm{~V} ; 1.00 \mathrm{~V} \leqslant E_{\mathrm{u}} \leqslant 1.40 \mathrm{~V}$ and $0.5 \mathrm{kHz} \leqslant f \leqslant 6.25 \mathrm{kHz}$.

In order to have a negligible influence of the adsorbed hydrogen-dissolved hydrogen equilibrium, the lowest value of $E_{1}$ was taken as $0.2 \mathrm{~V}$. Under the worst conditions, namely $E_{1}=0.2 \mathrm{~V}$ and $v=0.1 \mathrm{~V} / \mathrm{s}$, the ratio of the charges of adsorbed hydrogen and dissolved hydrogen in the first layer of Pd atoms formed cathodically for $10 \mathrm{~s}$ or $1 \mathrm{~s}$ is about $10^{3}$ [18]. Therefore, the question of the hydrogen equilibrium at the Pd surface with bulk hydrogen does not become relevant for the purposes of the present work.

The amount of metal dissolved under these circumstances was evaluated through atomic absorption by using a Jarrell-Ash $82-519$ spectrometer. The corresponding standard Pd(II) solution was prepared by dissolving a piece of $\mathrm{Pd}$ wire in aqua regia. Afterwards the solution was evaporated to obtain a dry residue, which was then dissolved in concentrated $\mathrm{HCl}$ [19]. This procedure was repeated several times to avoid the formation of nitric acid-Pd compounds. Finally, the solid $\mathrm{PdCl}_{2}$ residue was dissolved in water and its concentration was determined gravimetrically through the dimethylglioxime reaction [20]. The concentration of dissolved Pd produced in the electrochemical treatment was obtained by using the entire electrolyte solution. Eventually the graphite counter electrode was tested for any Pd residue produced in the course of the electrochemical treatment.

SEM images of the treated surfaces were made under conventional ex-situ conditions and the change in real surface area was determined through the voltammetric electroreduction charge of the O-containing surface species electroformed under preset conditions. Scanning electron tunneling microscopy (STM) images at the nanometer level were also obtained, particularly to discover the topographic details related to the surface modifications resulting after the electrochemical treatment.

(III) RESULTS

\section{(III.I) Evaluation of Pd electrodissolution during potential cycling}

In principle, the metal electrodissolution caused by the application of a periodic potential can be expressed either as the integral specific metallic corrosion rate $\left(v_{\mathrm{T}}\right)$ 


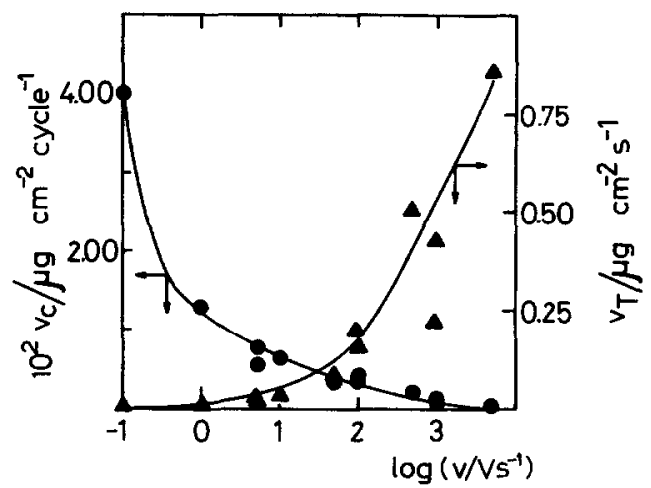

Fig. 1. Plots of $v_{\mathrm{c}}$ and $v_{\mathrm{T}}$ vs. $\log v$ RTPS. $E_{\mathrm{u}}=1.40 \mathrm{~V}, E_{1}=0.33 \mathrm{~V}$.

in $\mu \mathrm{g} \mathrm{s}^{-1} \mathrm{~cm}^{-2}$, or as the specific metallic corrosion per cycle $\left(v_{\mathrm{c}}\right)$ in $\mu \mathrm{g} \mathrm{cycle}^{-1}$ $\mathrm{cm}^{-2}$. It is clear that under preset $E_{\mathrm{u}}$ and $E_{1}, v_{\mathrm{T}}$ for $\mathrm{Pd}$ in $1 M \mathrm{H}_{2} \mathrm{SO}_{4}$ increases but $v_{\mathrm{c}}$ decreases as $v$ increases (Fig. 1). Results obtained by changing systematically either $E_{\mathrm{u}}$ or $E_{1}$ are shown in Table 1 . As expected, these results are only slightly dependent on the waveform of the periodic potential. The amounts of $\operatorname{Pd}$ (II) in solution evaluated from these runs in the $\mathrm{kHz}$ range were always nearly 100 times lower than that determined at lower frequency $(v=0.1 \mathrm{~V} / \mathrm{s} ; f=0.05 \mathrm{~Hz})$.

\section{(III.2) Voltammetry and SEM micrographs of treated Pd electrodes}

The sequence of voltammograms of $\mathrm{Pd}$ in $1 \mathrm{M} \mathrm{H}_{2} \mathrm{SO}_{4}$, at $0.1 \mathrm{~V} / \mathrm{s}$ and $25^{\circ} \mathrm{C}$, depends strongly on the previous electrode treatment. Thus, a typical repetitive

\section{TABLE 1}

Palladium dissolution data from runs made with RSWPS treatment either for constant potential limits and different frequencies or for a constant frequency and variable potential windows

\begin{tabular}{lclll}
\hline$E_{\mathrm{u}} / \mathrm{V}$ & $E_{1} / \mathrm{V}$ & $f / \mathrm{kHz}$ & $\begin{array}{l}10^{-3} v_{\mathrm{c}} / \\
\mu \mathrm{g} \mathrm{cm}^{-2} \mathrm{cycle}^{-1}\end{array}$ & $v_{\mathrm{T}} / \mu \mathrm{g} \mathrm{cm}^{-2} \mathrm{~s}^{-1}$ \\
\hline $\begin{array}{l}\text { (a) Influence of the frequency } \\
1.40\end{array}$ & 0.33 & 0.50 & 1.0 & 0.50 \\
1.40 & 0.33 & 1.00 & 0.41 & 0.42 \\
1.40 & 0.33 & 2.10 & 0.29 & 0.60 \\
1.40 & 0.33 & 3.12 & 0.40 & 1.25 \\
1.40 & 0.33 & 6.20 & 0.41 & 2.55 \\
\multicolumn{5}{l}{ (b) Influence of the potential limits } \\
1.40 & 0.20 & 3.12 & & \\
1.20 & 0.33 & 3.12 & 0.08 & 0.25 \\
1.00 & 0.33 & 3.12 & 0.053 & 0.16 \\
1.20 & 0.60 & 3.12 & 0.012 & 0.035 \\
\end{tabular}



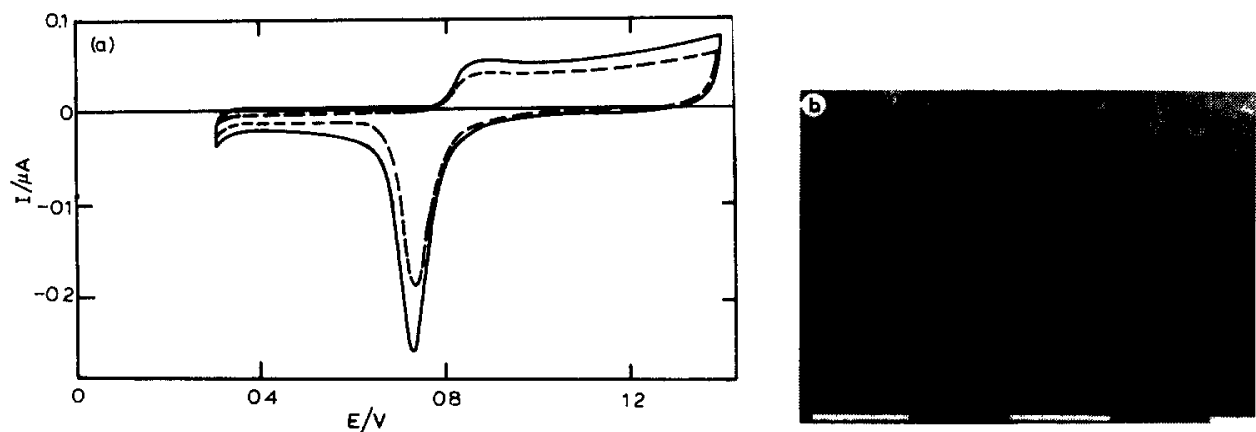

Fig. 2. (a) Voltammograms run at $0.1 \mathrm{~V} / \mathrm{s}$ in $1 \mathrm{M} \mathrm{H}_{2} \mathrm{SO}_{4}$ at $25^{\circ} \mathrm{C}$

) After $30 \mathrm{~min}$ RTPS at 0.1 $\mathrm{V} / \mathrm{s}$ between $E_{1}=0.33 \mathrm{~V}$ and $E_{\mathrm{u}}=1.40 \mathrm{~V}$. (- - - ) After $60 \mathrm{~min}$ RTPS at $0.1 \mathrm{~V} / \mathrm{s}$ between $E_{1}=0.33$ $\mathrm{V}$ and $E_{\mathrm{u}}=1.40 \mathrm{~V}$. Geometric electrode area $0.2 \mathrm{~cm}^{2}$. (b) SEM pattern (scale $10 \mu \mathrm{m}$ ), untreated Pd surface.

voltammogram of an untreated Pd electrode (Fig. 2) (blank), exhibits a broad electrooxidation peak located at $0.86 \mathrm{~V}$ (peak I) and an anodic current which increases steadily from ca. $1.0 \mathrm{~V}$ upwards, and a sharp and symmetric electroreduction peak at $0.77 \mathrm{~V}$. This voltammogram always changes slightly during cycling as described in a previous publication [21], although these changes are comparatively less important than those produced by the application of the electrochemical treatment. SEM micrographs of untreated Pd electrodes (Fig. 2b) exhibit the kind of topography already described for polycrystalline fcc metal electrodes made by melting the metal wire in an oxygen-gas flame [22].

The conventional voltammograms of $\mathrm{Pd}$ in $1 \mathrm{M} \mathrm{H}_{2} \mathrm{SO}_{4}$ at $0.1 \mathrm{~V} / \mathrm{s}$ after the electrochemical treatment can be grouped as follows:

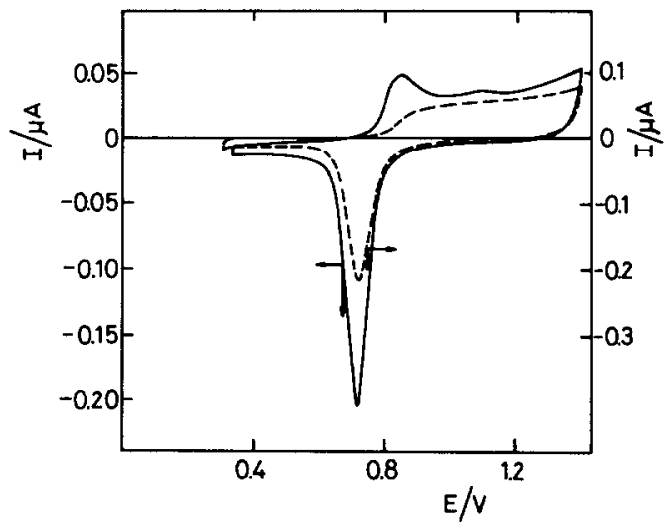

Fig. 3. Voltammogram run at $0.1 \mathrm{~V} / \mathrm{s}$ in $1 \mathrm{M} \mathrm{H}_{2} \mathrm{SO}_{4}$ at $25^{\circ} \mathrm{C}$. (- - ) After $15 \mathrm{~min} \mathrm{RTPS}$ at $0.1 \mathrm{~V} / \mathrm{s}$, $E_{1}=0.33 \mathrm{~V}, E_{\mathrm{u}}=1.40 \mathrm{~V}$. ( $(\longrightarrow)$ After $3 \mathrm{~h} \mathrm{RTPS}$ at $1 \mathrm{~V} / \mathrm{s}, E_{1}=0.33 \mathrm{~V}, E_{\mathrm{u}}=1.40 \mathrm{~V}$. Geometric electrode area $0.2 \mathrm{~cm}^{2}$. 
TABLE 2

Data on the increase of $R$ during the RTPS treatment

\begin{tabular}{rll}
\hline$v / \mathrm{V} \mathrm{s}^{-1}$ & $t / \mathrm{h}$ & $R=\frac{Q_{\text {r,treated }} \text { a }}{Q_{\text {r,untreated }}}$ \\
\hline 5 & 6 & 2.2 \\
10 & 7 & 2.3 \\
50 & 2.33 & 4.0 \\
100 & 1 & 4.5 \\
500 & 1 & 3.5 \\
1000 & 2.17 & 5.3 \\
5000 & 1 & 2.5 \\
\hline
\end{tabular}

$Q_{\mathrm{r}}=$ voltammetric electroreduction charge of O-containing species.

(a) Voltammograms resulting after $12 \mathrm{~h}$ RTPS treatment at $v<1 \mathrm{~V} / \mathrm{s}$ between $0.33 \mathrm{~V}$ and $1.40 \mathrm{~V}$ (Figs. $2 \mathrm{a}$ and 3). These comprise charges, both anodic and cathodic, smaller than those of the blank. They also exhibit a clear improvement in the resolution of peak I and a new peak (II) appears at $1.10 \mathrm{~V}$.

(b) Voltammograms resulting from the RTPS treatment in the $0.33-1.40 \mathrm{~V}$ range and $5 \mathrm{~V} / \mathrm{s} \leqslant v \leqslant 5000 \mathrm{~V} / \mathrm{s}$ range, where the voltammetric charge with respect to the blank $(R)$ resulting at $0.1 \mathrm{~V} / \mathrm{s}$ increases as indicated in Table 2 . Here, peaks I and II are also reasonably well resolved.

(c) Voltammograms resulting from RSWPS treatments between $0.33 \mathrm{~V}$ and 1.40 $\mathrm{V}$, and frequencies ranging from $0.5 \mathrm{kHz}$ to $6.25 \mathrm{kHz}$. These treatments modify the Pd electrode behaviour in such a way that already for $t=5 \mathrm{~min}$ the corresponding voltammogram at $0.1 \mathrm{~V} / \mathrm{s}$ in $1 \mathrm{M} \mathrm{H}_{2} \mathrm{SO}_{4}$ (Figs. 4a,b) becomes similar to that reported for palladised $\mathrm{Pt}$ electrodes [23], i.e. the H-atom electroadsorption-electrodesorption reaction exhibits a characteristic pair of conjugated reversible current peaks. It is thus entirely reasonable to expect the surface features to be prominent only when the amount of surface adsorption is large compared to $\mathrm{H}$ absorption in the bulk [24,25]. On the other hand, as $E_{\mathrm{u}}$ is decreased from $1.4 \mathrm{~V}$ to $1.0 \mathrm{~V}$, the $H$-adatom voltammetric peaks are no longer observed. In this case the value of $R$ is about 1.6, both peaks I and II are again clearly resolved, and peak I becomes sharper as $f$ decreases. Likewise, the height of peak II decreases rapidly during potential cycling at $0.1 \mathrm{~V} / \mathrm{s}$. The SEM micrographs of these electrode surfaces (Figs. $4 c$,d) exhibit an apparently smooth surface region with randomly distributed pit-like holes of different sizes with rather thick boundaries, and small globules which presumably are sites of formation of new pit-like holes. At a higher magnification apparently smooth regions (actually consisting of an overlayer of nearly spherical sticking particles) can be observed. According to the voltammetric charge increases observed for these electrodes, the overlayer is apparently made of a fine dispersion of palladium produced through the electrodeposition of $\mathrm{Pd}(\mathrm{II})$ soluble species, resulting in this case from the periodic potential treatment. The presence of Pd soluble species presumably accounts for the relatively important shift of the base 

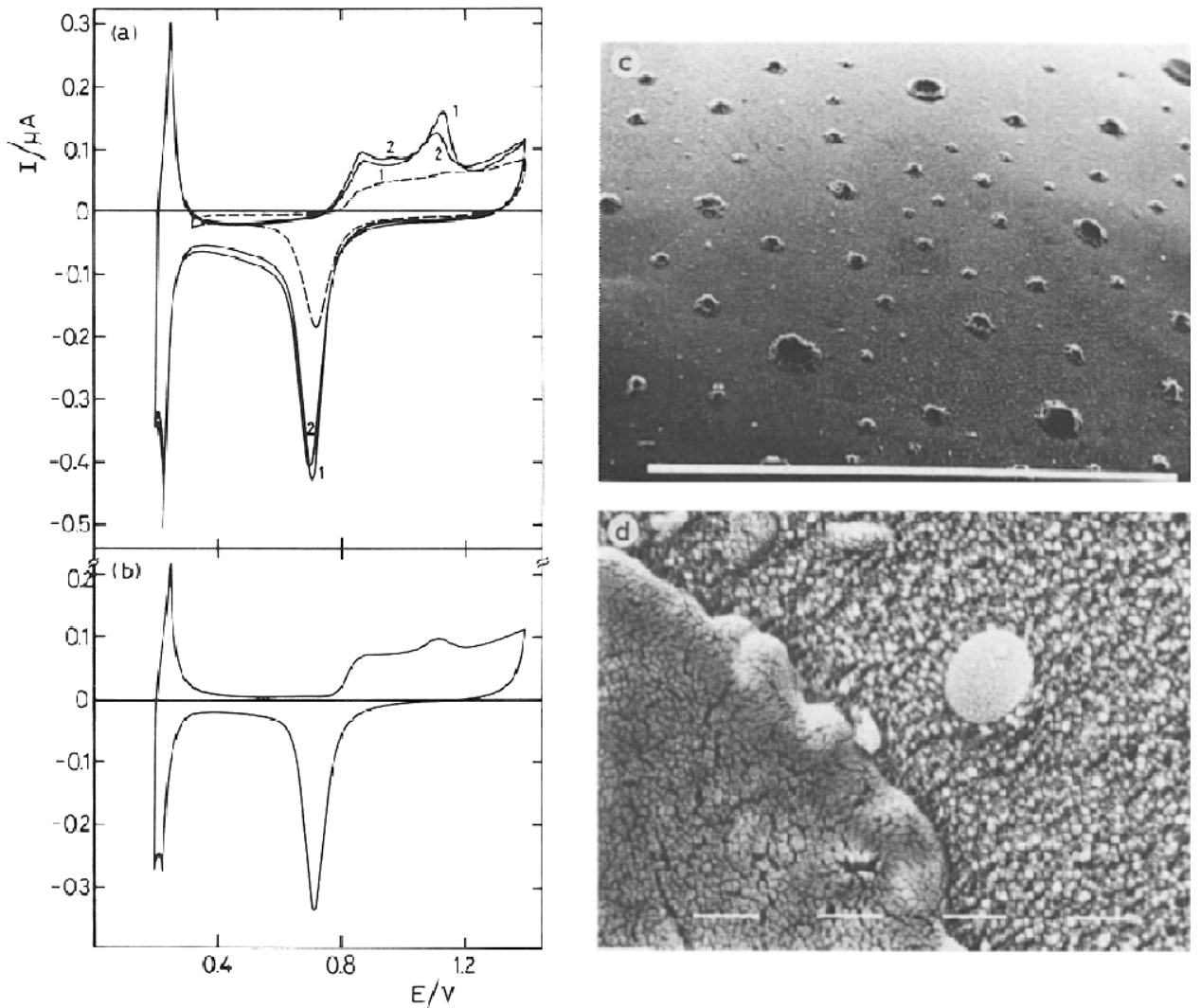

Fig. 4. Voltammogram runs at $0.1 \mathrm{~V} / \mathrm{s}$ in $1 \mathrm{M} \mathrm{H}_{2} \mathrm{SO}_{4}$ at $25^{\circ} \mathrm{C}$. Geometric electrode area $0.2 \mathrm{~cm}^{2}$. (a) $\left(--\right.$, ) After $15 \mathrm{~min}$ RTPS at $0.1 \mathrm{~V} / \mathrm{s} ;(-)$ after RSWPS at $f=3.12 \mathrm{kHz}, E_{1}=0.33 \mathrm{~V}$, $E_{\mathrm{u}}=1.40 \mathrm{~V}, t=23 \mathrm{~min}$. (1) and (2) denote first and second cycle, respectively. (b) Response of the same electrode after RTPS at $0.1 \mathrm{~V} / \mathrm{s}$ for $5 \mathrm{~min}$ in fresh $1 \mathrm{M} \mathrm{H}_{2} \mathrm{SO}_{4}$. (c) SEM pattern (scale $0.1 \mathrm{~mm}$ ) after 5 $\min$ RSWPS at $3.12 \mathrm{kHz}, E_{1}=0.33 \mathrm{~V}, E_{\mathrm{u}}=1.40 \mathrm{~V}$. (d) SEM pattern (scale $1 \mu \mathrm{m}$ ) after $5 \mathrm{~min}$ RSWPS at $3.12 \mathrm{kHz}, E_{1}=0.33 \mathrm{~V}, E_{\mathrm{u}}=1.40 \mathrm{~V}$.

line shown in Figs. 3 and 4. This explanation seems to be confirmed by the results shown in the sequence of Figs. 4a,b, where the cathodic current decreases in going from the first to the second potential scan and becomes even smaller in a fresh electrolyte solution.

(d) Voltammograms of Pd electrodes subjected to RSWPS treatments for $E_{\mathrm{u}}=$ $1.20 \mathrm{~V}$ and $E_{1}=0.60 \mathrm{~V}$, at $3.1 \mathrm{kHz} \leqslant f \leqslant 5.0 \mathrm{kHz}$, during 3 to $5 \mathrm{~min}$. The voltammetric response of the RSWPS treated electrodes changes according to the number of cycles at $0.1 \mathrm{~V} / \mathrm{s}$, as seen in Fig. Sa. The initial electroreduction cycle exhibits a very large current in the $0.35-0.55 \mathrm{~V}$ range related to the electroreduction of a $\mathrm{Pd}(\mathrm{II})$ hydroxide species accumulated during the oxidation-reduction cycles. Subsequently, the voltammetric charge increases with the duration of the electro- 

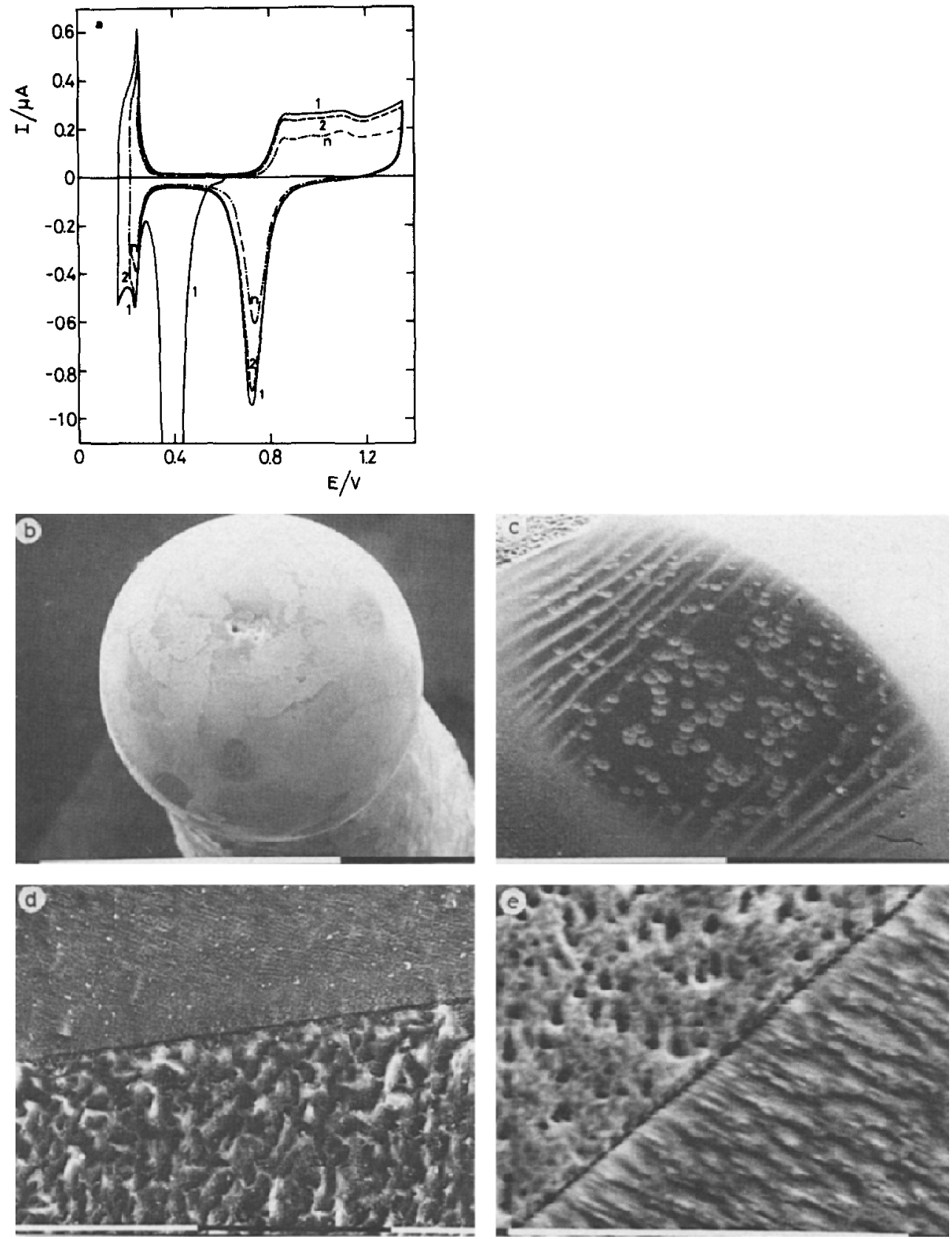

Fig. 5. (a) Voltammogram run at $0.1 \mathrm{~V} / \mathrm{s}$ in $1 \mathrm{M} \mathrm{H}_{2} \mathrm{SO}_{4}$ at $25^{\circ} \mathrm{C}$. Geometric electrode area $0.05 \mathrm{~cm}^{2}$. (- - First cycle after $5 \mathrm{~min}$ RSWPS at $5 \mathrm{kHz}$ between $E_{1}=0.60 \mathrm{~V}$ and $E_{\mathrm{u}}=1.20 \mathrm{~V}$. (- - - ) Second cycle. (.--・) After $5 \mathrm{~min}$ RTPS at $0.1 \mathrm{~V} / \mathrm{s}$. (b-e) SEM pattern after $5 \mathrm{~min}$ RSWPS at $5 \mathrm{kHz}$; $E_{1}=0.60 \mathrm{~V}, E_{\mathrm{u}}=1.20 \mathrm{~V}$; (b) scale $1 \mathrm{~mm}$; (c) scale $0.1 \mathrm{~mm}$; (d) scale $10 \mu \mathrm{m}$; (e) scale $10 \mu \mathrm{m}$. 

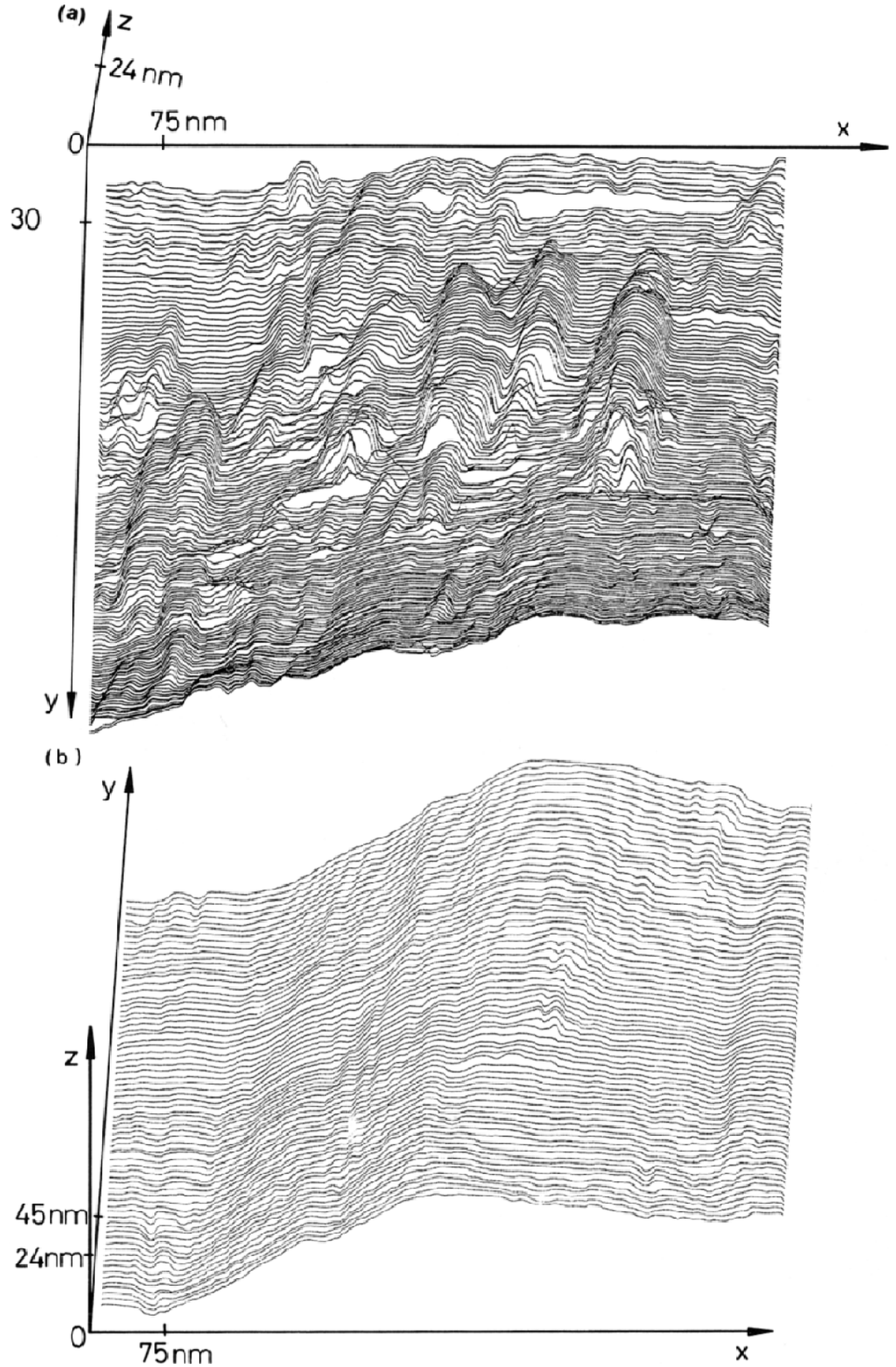

Fig. 6. Scanning tunneling microscope images resulting under ex-situ conditions. RSWPS treated Pd, $E_{1}=0.60 \mathrm{~V} ; E_{\mathrm{u}}=1.20 \mathrm{~V}, f=5 \mathrm{kHz}$. (a) High step density surface region. (b) Relatively smooth (nm level) surface region. 
chemical treatment up to a maximum value of $R$ comprised between 5 and 20, and later $R$ decreases progressively during RTPS at $0.1 \mathrm{~V} / \mathrm{s}$ (Fig. 5a). Again, in this case a trend of the voltammetric behaviour of the electrode towards that of palladiated surfaces can be seen. The SEM images of these electrodes (Figs. 5b-e) show the appearance of crystallographic poles at the different grains of the Pd microelectrode. One of these poles exhibits a nearly-parallel channel-like structure with pits. Some grains present faces with a sponge-like structure and others with clear electrochemically faceted regions. The STM images of these surfaces (Figs. 6a,b) show a structure of parallel steps and flat terraces with an average height of about $10-15 \mathrm{~nm}$ and a step separation of about $20-80 \mathrm{~nm}$. These structures are comparable to those reported recently for the preferred crystallographic orientation of $\mathrm{Pt}$ and $\mathrm{Au}$ surfaces $[26,27]$.

(IV) DISCUSSION

(IV.1) The electrochemical treatment condition of $\mathrm{Pd}$ in $\mathrm{H}_{2} \mathrm{SO}_{4}$ solution and thermodynamic data

The application of periodic potentials to Pd electrodes immersed in $1 \mathrm{M} \mathrm{H}_{2} \mathrm{SO}_{4}$ produces a series of modifications at the metal surface which can be followed through both voltammetry at $0.1 \mathrm{~V} / \mathrm{s}$ in the $0.20-1.40 \mathrm{~V}$ range and surface imaging techniques. These modifications imply (i) a change in roughness with a sintering effect; (ii) the formation of a palladised Pd surface structure; and (iii) the formation of a Pd(II) hydroxide layer which can be electroreduced slowly, yielding a reduced metal modified surface with a change in roughness.

The modifications produced on Pd through periodic potential treatments can be qualitatively comparable only to those found on Pt [4], the operating conditions for roughening and electrochemical faceting of $\mathrm{Pd}$ still not being so well characterized as was the case for Pt. The amount of Pd going into solution is about 100 times greater than that of $\mathrm{Pt}$ so that the relatively large solubility of $\mathrm{Pd}$ salts, in this case $\mathrm{PdSO}_{4}$, probably interferes in the overall process, making the clear separation of the different effects difficult at the present stage. In addition the fact that the absorption of both $\mathrm{H}$ and $\mathrm{O}$ into $\mathrm{Pd}$ is also greater than for $\mathrm{Pt}$ might introduce some uncertainty about the cleanness of the initial Pd surface.

In order to find out the probable mechanism associated with the different changes referred to above, let us first consider the location of the potential window of the waveforms applied to the electrode with respect to the equilibrium potentials of the possible reactions involving $\mathrm{Pd}(0), \mathrm{Pd}(\mathrm{II})$ and O-containing Pd species (Table 3). Comparison of these equilibrium potentials with the potential limits of either RTPS or RSWPS, indicates that each period of the electrochemical treatment comprises net electrooxidation and electroreduction reactions occurring in the positive and negative half cycles, respectively. The times $\left(\tau_{a}^{\prime}\right)$ and $\left(\tau_{c}^{\prime}\right)$ related to the 
TABLE 3

Standard potentials of reactions involving $\mathrm{Pd}$ - and $\mathrm{Pd}-\mathrm{O}$-containing species

\begin{tabular}{lll}
\hline Reaction & $E^{\circ} / \mathrm{V}$ & Reference \\
\hline (1) $\mathrm{Pd}(\mathrm{OH})_{\mathrm{ad}}+\mathrm{H}^{+}+e^{-} \rightleftarrows \mathrm{Pd}+\mathrm{H}_{2} \mathrm{O}$ & 0.82 & 29 \\
(2) $\mathrm{Pd}(\mathrm{OH})_{2}+2 \mathrm{H}^{+}+2 e^{-} \rightleftarrows \mathrm{Pd}+2 \mathrm{H}_{2} \mathrm{O}$ & 0.897 & 28 \\
(3) $\mathrm{PdO}+2 \mathrm{H}^{+}+2 e^{-\rightleftarrows \mathrm{Pd}+\mathrm{H}_{2} \mathrm{O}}$ & 0.917 & 28 \\
& 0.79 & 28 \\
(4) $\mathrm{Pd}^{2+}+2 e^{-} \rightleftarrows \mathrm{Pd}$ & 0.915 & 28 \\
& 0.987 & 28 \\
(5) $\mathrm{PdO}_{2}+4 \mathrm{H}^{+}+4 e^{-} \rightleftarrows \mathrm{Pd}+2 \mathrm{H}_{2} \mathrm{O}$ & 0.945 & 28 \\
\end{tabular}

anodic and cathodic reactions can be evaluated through the RTPS experiments, by using the following relationships:

$\tau_{\mathrm{a}}^{\prime}=2\left(E_{\mathrm{u}}-E^{\circ}\right) / v$

and

$\tau_{\mathrm{c}}^{\prime}=2\left(E^{\circ}-E_{1}\right) / v$

where $E^{\circ}$ is the potential of the triggering reversible reaction, which for the present case is taken as that of reaction (1) shown in Table 3. In this way $\tau_{\mathrm{a}}^{\prime}$ and $\tau_{\mathrm{c}}^{\prime}$ for the RTPS treatment can be compared directly to $\tau_{\mathrm{u}}$ and $\tau_{1}$ for the RSWPS treatment.

\section{(IV.2) Analysis of the different rate controlled regions}

Let us consider the symmetric RTPS and RSWPS treatments where $\tau_{\mathrm{a}}^{\prime} \simeq \tau_{\mathrm{c}}^{\prime}$ and $\tau_{\mathrm{u}}=\tau_{1}$, respectively, and let $E_{1}$ be located in the potential range where according to thermodynamics (Table 3 ) palladium species can be electroreduced completely, i.e. $E_{1}=0.33 \mathrm{~V}$, and $E_{\mathrm{u}}$ be set in the potential range where the electroformation of $\operatorname{Pd}(\mathrm{II})$ species becomes possible, i.e. $E_{\mathrm{u}}=1.40 \mathrm{~V}$. In this case, when the values of $v_{\mathrm{T}}$ and $v_{c}$ are displayed in $\log -\log$ plots (Fig. 7), different parametric relationships can be derived depending on the range of $\tau_{i}^{\prime}(i=\mathrm{a}, \mathrm{c})$. Thus, four regions can be distinguished namely for $10 \mathrm{~s}>\tau_{i}^{\prime}>0.1 \mathrm{~s}$ (region I), for $0.1 \mathrm{~s}>\tau_{i}^{\prime}>3 \times 10^{3} \mathrm{~s}$ (region II), an abrupt change (region III) confined to a small $\Delta \tau_{i}^{\prime}$ range at about $10^{-3} \mathrm{~s}$ and for $3 \times 10^{-3} \mathrm{~s}>\tau_{t}^{\prime}$ (region IV). It is convenient for the sake of clarity to discuss the results found in the different regions independently.

\section{(IV.2.i) Kinetics of processes accurring in region $I$}

In region I, $v_{\mathrm{T}}$ increases and $v_{\mathrm{c}}$ decreases with $\tau^{1 / 2}\left(\Delta \log v_{\mathrm{T}} / \Delta \log \tau_{i}^{\prime}=\frac{1}{2}\right.$ and $\Delta \log v_{\mathrm{c}} / \Delta \log \tau_{i}^{\prime}=-\frac{1}{2}$ ), and the treated Pd surface exhibits no substantial changes in the voltammetric charge, although the O-electroadsorption process reveals net changes in Pd surface reactivity. The relationship resulting in region I agree with the fact that the rate of $\mathrm{Pd}$ electrodissolution as followed through $v_{\mathrm{T}}$ is under bulk diffusion control through a pulsating diffusional boundary layer whose average 

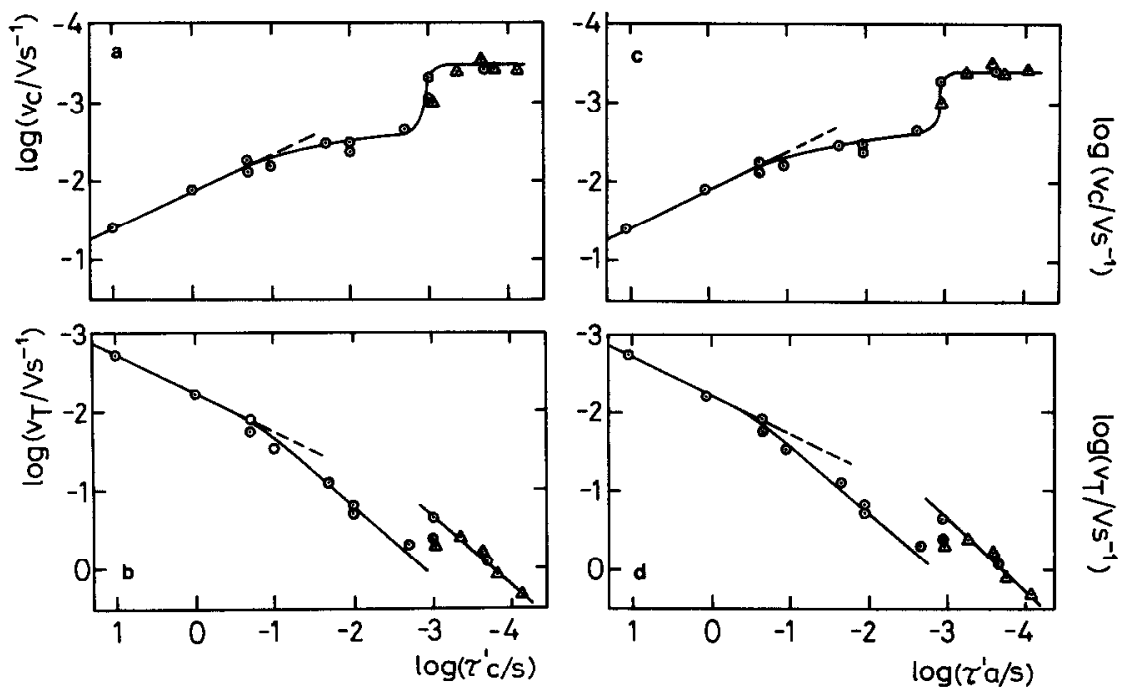

Fig. 7. Palladium electrodissolution plots. (a) $\log v_{\mathrm{c}}$ vs. $\log \tau_{\mathrm{c}}^{\prime}$ plots; (b) $\log v_{\mathrm{T}}$ vs. $\log \tau_{\mathrm{c}}^{\prime}$ plots; (c) $\log v_{\mathrm{c}}$ vs. $\log \tau_{\mathrm{a}}^{\prime}$ plots; (d) $\log v_{\mathrm{T}}$ vs. $\log \tau_{\mathrm{a}}^{\prime}$ plots. (O) RTPS; ( $\triangle$ RSWPS. $E_{\mathrm{u}}=1.40 \mathrm{~V}, E_{1}=0.33 \mathrm{~V}$.

thickness, $\delta_{\mathrm{p}}$, which lies in the $10^{-2}-10^{-3} \mathrm{~cm}$ range, decreases according to $\tau_{i}^{\prime 1 / 2}$ [30]. It should be noticed that these values of $\delta_{\mathrm{p}}$ are not very much different from those corresponding to the thickness of the diffusional boundary layers at the rotating [31] and vibrating [32] disc electrodes at low frequencies.

Let us consider the processes occuring during an electrochemical single sweep treatment. The following processes take place during the interval $t=0$ to $t=\tau_{\mathrm{a}}^{\prime}$ : (i) the electrooxidation of $\mathrm{Pd}$ occurring through the intermediate $\mathrm{Pd}(\mathrm{OH})_{\mathrm{ad}}$, yielding O-containing surface species and soluble $\mathrm{Pd}^{2+}$; (ii) the diffusion and migration of $\mathrm{Pd}(\mathrm{II})$ ions into the solution assisted by the electric field at the interface; (iii) the appearance of soluble $\operatorname{Pd}(\mathrm{II})$ species in bulk solution $\left(\Delta c_{\mathrm{a}}\right)$, and the corresponding build-up of the diffusional boundary layer $\left(\delta_{\mathrm{p}, \mathrm{a}}\right)$ under conditions comparable to those described for monodirectional outward diffusion perpendicular to the surface of a plate electrode [33]. Subsequently, during the interval $t=\tau_{\mathrm{a}}^{\prime}$ to $t=\tau_{\mathrm{c}}^{\prime}$ the following rate processes occur: (i) the electroreduction of both O-containing surface and soluble $\mathrm{Pd}(\mathrm{II})$ species present within the volume of solution attached to the electrode whose average thickness is related to $\delta_{\mathrm{p}, \mathrm{c}}$ where $\delta_{\mathrm{p}, \mathrm{c}}<\delta_{\mathrm{p}, \mathrm{a}}$; (ii) the depletion of $\mathrm{Pd}(\mathrm{II})$ soluble species at the electrode surface caused by diffusion and migration slowed down by the electric field at the interface $\left(\Delta c_{c}\right)$; (iii) the possible reactions involving contributions of $\mathrm{Pd}(\mathrm{II})$ soluble species resulting from some oxide layer electroreduction. Simulation of the relaxation of the diffusional boundary layer for metal dissolution in the absence of metal ions in solution [34] shows that under a steady regime the concentration profile at the electrode surface fluctuates between two limiting situations defined for each half cycle of the periodic potential, and the result of the entire mass transport process during the potential cycling is 
that $\mathrm{Pd}(\mathrm{II})$ soluble species are being pumped into solution $\left(\Delta c_{\mathrm{s}}\right)$, so that for each cycle:

$\Delta c_{\mathrm{a}}=\Delta c_{\mathrm{c}}+\Delta c_{\mathrm{s}}$

Therefore, in region $I$ the electrodissolution process is determined mainly by diffusion of soluble Pd(II) species in solution.

\section{(IV.2.ii) Kinetics of processes occurring in region II}

As $\tau_{i}^{\prime}$ decreases from $0.1 \mathrm{~s}$ to $3 \times 10^{-3} \mathrm{~s}$ one can observe a rapid decrease in the rate of change of $v_{\mathrm{c}}$ and a linear increase in $v_{\mathrm{T}}$ with $\tau_{i}^{\prime}$. This region implies principally an increase in surface roughness. To learn about the processes which are responsible for the electrode surface modifications in region II, attention should be focused on those runs made with both RTPS and RSWPS at $E_{\mathrm{u}}=1.40 \mathrm{~V}, E_{1}=0.33$ $\mathrm{V}$ and $f<0.5 \mathrm{kHz}$. In these cases, $v_{\mathrm{c}}$ approaches a limiting value $(0.50 \pm 0.1) \times 10^{-2}$ $\mu \mathrm{g} / \mathrm{cm}^{2}$ cycle, so that under these conditions $v_{\mathrm{T}}$ increases proportionally to the number of cycles. This situation becomes possible if the electrodissolution reaction in this frequency range becomes progressively more irreversible.

\section{(IV.2.iii) Kinetics of processes occurring in regions III and IV}

The abrupt transition in the $\log v_{\mathrm{c}}$ vs. $\log \tau_{i}^{\prime}$ and $\log v_{\mathrm{T}}$ vs. $\log \tau_{i}^{\prime}$ plots appearing for $\log \tau_{i}^{\prime} \simeq-3$ can be interpreted in terms of a change in the kinetics of the overall reaction. In this case bulk diffusional processes become sufficiently fast so that surface processes turn out to be kinetically relevant, particularly during the electroreduction half cycle. The transition in the kinetics of net electrodissolution is related to a threshold frequency close to $0.5 \mathrm{kHz}$, which corresponds to a time equal to $2 \times 10^{-3} \mathrm{~s}$. This figure can be compared reasonably to the half life time of the $\operatorname{Pd}(\mathrm{OH})_{\text {ad }}$ species resulting for the reaction:

$\mathrm{Pd}+\mathrm{H}_{2} \mathrm{O} \rightleftarrows \mathrm{Pd}(\mathrm{OH})_{\mathrm{ad}}+\mathrm{H}^{+}+e^{-}$

which has been estimated as $6 \times 10^{-3} \mathrm{~s}$ [29]. The subsequent reaction is the formation of $\mathrm{Pd}(\mathrm{II})$ ions in solution according to:

$\mathrm{Pd}(\mathrm{OH})_{\mathrm{ad}} \rightleftarrows \mathrm{PdOH}^{+}+e^{-}$

$\mathrm{PdOH}^{+} \rightleftarrows \mathrm{Pd}^{2+}+\mathrm{OH}^{-}$

Therefore, the electrochemical treatment implies anodic reactions (1) to (1b) during $\tau_{\mathrm{u}}$ or $\tau_{\mathrm{a}}^{\prime}$ and the complementary electrodeposition of soluble Pd(II) ions during $\tau_{1}$ or $\tau_{c}^{\prime}$ yielding the palladised Pd surface (Figs. 4c,d). The high local concentration of $\mathrm{Pd}(\mathrm{II})$ attained at these frequencies for $E_{\mathrm{u}}=1.4 \mathrm{~V}$ should be a consequence of the relatively large solubility of $\mathrm{PdSO}_{4}$ [35]. This fact determines a clear distinction in the behaviours of $\mathrm{Pd}$ and $\mathrm{Pt}$ to the electrochemical treatment at frequencies in the order of kHz since the solubility of $\mathrm{PtSO}_{4}$ is much lower than that of $\mathrm{PdSO}_{4}$ [35]. In addition at these frequencies during $\tau_{\mathrm{a}}^{\prime}$ or $\tau_{\mathrm{u}}$ and $\tau_{\mathrm{c}}^{\prime}$ or $\tau_{1}$ one should except that the anion concentration at the interface also fluctuates between a maximum value for 
$E_{\mathrm{u}}$ and a minimum value for $E_{1}$, without reaching equilibrium ionic adsorption conditions, as the time required for the latter is of the order of $1 \mathrm{~min}$ [36].

\section{(IV.3) The influence of anodic oxide layers}

By investigating the influence of $E_{\mathrm{u}}$ on $\Delta c_{\mathrm{s}}$ the survey of anodic reactions involved in the electrochemical treatment can be completed. Thus, when $E_{1}=0.33$ $\mathrm{V}$ and $E_{\mathrm{u}}$ decreases from $1.40 \mathrm{~V}$ to $1.00 \mathrm{~V}$, a remarkable decrease in $\Delta c_{\mathrm{s}}$ can be noticed (Table 1). One should remember that the appearance of soluble Pd(II) at $1.40 \mathrm{~V}$ has been demonstrated clearly through voltammetry and RRDE data $[10,11]$, whereas its concentration is drastically reduced at lower potentials where the formation of $\mathrm{Pd}(\mathrm{OH})_{\mathrm{ad}}$ and $\mathrm{Pd}(\mathrm{OH})_{2}$ becomes thermodynamically favourable. Therefore, the following reaction:

$\mathrm{Pd}(\mathrm{OH})_{\mathrm{ad}}+\mathrm{H}_{2} \mathrm{O} \rightleftarrows \mathrm{Pd}(\mathrm{OH})_{2}+\mathrm{H}^{+}+e^{-}$

appears to compete with reaction (1a). This means that for $E_{\mathrm{u}}=1.20 \mathrm{~V}$, the species accumulated at the surface should imply a Pd(II) hydroxide layer, presumably $\mathrm{Pd}(\mathrm{OH})_{2} \cdot x \mathrm{H}_{2} \mathrm{O}$, which can be electroreduced voltammetrically within a potential range slightly more positive than the potential range of the $\mathrm{H}$-adatom reactions (Fig. 5 ). In addition, the occurrence of reaction (2a) also leaves open the possibility that $\mathrm{Pd}(\mathrm{II})$ in solution could come from a reaction such as:

$\mathrm{Pd}(\mathrm{OH})_{2}+\mathrm{H}_{2} \mathrm{SO}_{4} \rightleftarrows \mathrm{PdSO}_{4}+2 \mathrm{H}_{2} \mathrm{O}$

which is favoured by the relatively large solubility of $\mathrm{PdSO}_{4}$. Reaction (2b) reflects perhaps the main effect expected from the nature of the electrolyte on the electrochemical treatment of Pd electrodes as compared for instance to Pt. Besides it should be noted that at potentials more positive than that of reaction (4) in Table 3 , reactions (1) and (2a) produce a local acidification which may assist the formation of soluble Pd(II) through a reaction such as reaction ( $2 b)$.

The coverage by the $\operatorname{Pd}(\mathrm{II})$ hydroxide layer predominates for $E_{\mathrm{u}}<1.20 \mathrm{~V}$ and 0.5 $\mathrm{kHz}<f<6.25 \mathrm{kHz}$, while the electrochemical formation of $\mathrm{Pd}(\mathrm{II})$ is promoted for $1.20 \mathrm{~V}<E_{\mathrm{u}}<1.4 \mathrm{~V}$ and $f>0.5 \mathrm{kHz}$. Upon electroreduction the Pd(II) hydroxide layer yields an electrodeposited $\mathrm{Pd}$ layer with an appreciable roughness.

Finally, it should be noted that by decreasing $E_{1}$ under constant $E_{\mathrm{u}}=1.4 \mathrm{~V}$ and $f=3.12 \mathrm{kHz}$, a sharp decrease in $\Delta c_{\mathrm{s}}$ is observed because a greater amount of electroreduced Pd is obtained and the corresponding reaction approaches the activation controlled kinetic conditions. At this frequency a similar situation can be observed by using a periodic RSWPS with $\tau_{1}>\tau_{\mathrm{u}}$ with increasing $\tau_{1} / \tau_{\mathrm{u}}$ ratios.

The influence of $E_{1}$ is also reflected clearly in the type of surface modification achieved through the electrochemical treatment. Let us consider two extreme situations of $E_{1}$, for $E_{\mathrm{u}}=1.2 \mathrm{~V}$ and $f=3.1 \mathrm{kHz}$. Thus, the first situation arises for $E_{1}=0.6 \mathrm{~V}$ where the main surface modification appears to be related to electrochemical faceting, and one should expect the electroreduction of surface oxide to be the main process during $\tau_{1}$. The resulting rough metal Pd surface is similar to that 
obtained through the processes described for the RTPS treatment in the $0.2-2.4 \mathrm{~V}$ range [37]. The fact that electrochemical faceting is produced seems to indicate that the electroreduction processes become adatom surface diffusion rate controlled, as predicted under certain conditions in the electrocrystallisation of metals [4]. Otherwise, for the second situation, that is for $0.20 \mathrm{~V} \leqslant E_{1} \leqslant 0.33 \mathrm{~V}$, a definite palladised Pd surface is brought forward. Under these circumstances the main cathodic process should be the electrodeposition of soluble Pd(II), although the net amount of the latter becomes smaller than in the case formerly discussed in Section IV.2. Therefore, the cathodic reaction comprises two different possibilities, namely either the predominant electrodeposition of $\mathrm{Pd}(\mathrm{II})$ yielding a palladised $\mathrm{Pd}$ electrode structure with an increase in surface roughening and sintering effects, or the slow electroreduction of the $\mathrm{Pd}(\mathrm{II})$ hydroxide layer and soluble $\mathrm{Pd}(\mathrm{II})$ electrodeposition yielding an electrodispersed-type Pd surface, exhibiting an appreciable degree of faceting.

The overall reactions describing the kinetics of processes in the frequency range up to $1 \mathrm{kHz}$ cannot, however, be applied straightforwardly at frequencies greater than $5 \mathrm{kHz}$ because as the values of $\tau^{\prime}$ are set smaller than the half life time of the initial $\operatorname{Pd}(\mathrm{OH})_{\mathrm{ad}}$ species, the conventional electrochemical reactions become progressively suppressed. A systematic investigation carried out recently in the range of $f$ greater than $10 \mathrm{kHz}$ for $\mathrm{Pt}$ in acid indicates that the electrochemical treatment at these frequencies changes the effect into a kind of annihilation of surface defects without preferred orientation and roughening [38,39]. This matter deserves further consideration when experimental results in the high frcquency range for Pd become available in the near future.

\section{ACKNOWLEDGEMENT}

This work was supported financially by the Consejo Nacional de Investigaciones Científicas y Técnicas and the Comisión de Investigaciones Científicas de la Provincia de Buenos Aires. The authors are indebted to Profs. N. Garcia and A. Baró and co-workers, Departamento de Física, Universidad Autónoma de Madrid, Spain, for making available the facilities for running the STM images.

\section{REFERENCES}

1 R.M. Cerviño, W.E. Triaca and A.J. Arvia, J. Electroanal. Chem., 182 (1985) 51.

2 J.C. Canullo, W.E. Triaca and A.J. Arvia, J. Electroanal. Chem., 175 (1984) 337.

3 W.E. Triaca, J.C. Canullo, T. Kessler and A.J. Arvia, J. Electrochem. Soc., 134 (1987) 1165.

4 A. Visintin, W.E. Triaca and A.J. Arvia, J. Electroanal. Chem., 221 (1987) 239.

5 E.V. Albano, H.O. Martín and A.J. Arvia, Phys. Rev., 35 (1987) 9341.

6 D.A.J. Rand and R. Woods, J. Electroanal. Chem., 35 (1972) 209.

7 S.H. Cadle, J. Electrochem. Soc, 121 (1974) 645.

8 J.F. Llopis, J.M. Gamboa and L. Victori, Electrochim. Acta, 17 (1972) 2225.

9 K.J. Vetter and D. Berndt, Z. Elektrochem., 62 (1958) 378.

10 A.E. Bolzan, M.E. Martins and A.J. Arvia, J. Electroanal. Chem., 172 (1984) 221.

11 A.E. Bolzan, M.E. Martins and A.J. Arvia, J. Electroanal. Chem., 207 (1986) 279.

12 T.R. Blackburn and J.J. Lingane, J. Electroanal. Chem., 5 (1963) 216. 
13 H.R. Conrad, G. Ertl, J. Küppers and E.E. Latta, Surf. Sci., 65 (1977) 245.

14 T.W. Orent and S.D. Bader, Surf. Sci., 115 (1982) 323.

15 C.L. Perdriel, M. Ipohorsky and A.J. Arvia, J. Electroanal. Chem., 215 (1986) 317.

16 E. Custidiano, S. Piovano, A.J. Arvia, A.C. Chialvo and M. Ipohorsky, J. Electroanal. Chem., 221 (1987) 229.

17 C.L. Perdriel, W.E. Triaca and A.J. Arvia, J. Electroanal. Chem., 205 (1986) 279.

18 M.W. Breiter, J. Electroanal. Chem., 81 (1977) 275.

19 G. Brauer, Handbuch der Präparativen Anorganischen Chemie, Vol. 2, Ferdinand Enke, Stuttgart, 1967.

20 I.M. Kolthoff, E.B. Sandell, E.J. Meehan and S. Bruckenstein, Análisis Químico Cuantitativo, Nigar, Madrid, 1972.

21 A.E. Bolzan, M.E. Martins and A.J. Arvia, J. Electroanal. Chem., 157 (1983) 339.

22 J.C. Canullo, W.E. Triaca and A.J. Arvia, J. Electroanal. Chem., 200 (1986) 397.

23 B.S.Ya. Vasina, S.B. Moreano, O.A. Petrii, V.J. Kondrashova and M.I. Zhirhova, Elektrokhimiya, 19 (1983) 795.

24 L.A. Harris, J. Electrochem. Soc., 129 (1982) 2689.

25 J.P. Chevillot, J. Farcy, Ch. Hinnen and A. Rousseau, J. Electroanal. Chem., 64 (1975) 39.

26 J. Gómez, L. Vázquez, A.M. Baró, N. García, C.L. Perdriel, W.E. Triaca and A.J. Arvia, Nature (London), 323 (1986) 612.

27 J. Gómez, A.M. Baro, C.L. Perdriel and A.J. Arvia, in preparation.

28 F. Colom in A.J. Bard, R. Parsons and J. Jordan (Eds.), Standard Potentials in Aqueous Solution, IUPAC, Marcel Dekker, New York and Basel, 1986, p. 339.

29 A.E. Bolzan, A.C. Chialvo and A.J. Arvia, J. Electroanal. Chem., 179 (1984) 71.

30 J.C. Piuppe and N. Ibl, J. Appl. Electrochem., 10 (1980) 775.

31 V. Levich, Physicochemical Hydrodynamics, Prentice-Hall, Englewood Cliffs, NJ, 1962.

32 G.F. Paús, J.J. Podestă and A.J. Arvia, Electrochim. Acta, 31 (1986) 399.

33 P. Delahay, New Instrumental Methods in Electrochemistry, Interscience, New York, 1954.

34 S.L. Marchiano and A.J. Arvia, in preparation.

35 R.C. Weast (Ed.), Handbook of Chemistry and Physics, 57th ed., CRC Press, Cleveland, OH, 1977 p. B-138.

36 M.I. Florit, M.E. Martins and A.J. Arvia, J. Electroanal. Chem., 151 (1983) 209.

37 A.E. Bolzan, A.C. Chialvo and A.J. Arvia, in preparation.

38 T. Kessler, A.M. Castro Luna, W.E. Triaca and A.J. Arvia, J. Appl. Electrochem., 16 (1986) 693.

39 A. Visintin, J.C. Canullo, W.E. Triaca and A.J. Arvia, J. Electroanal. Chem., 239 (1988) 67. 